Res Publica. Revista de Historia de las Ideas Políticas ISSN-e: 1989-6115

http://dx.doi.org/10.5209/RPUB.63885

\title{
Comunicación retórica en las crónicas del siglo xvi. Escritura normativa en las Repúblicas del mundo de Fray Jerónimo Román Zamora
}

\author{
Marcos Santiago Cuautle Aguilar*
}

Recibido: 17 de enero de 2018 / Aceptado: 14 de diciembre de 2018

Resumen. El agustino Jerónimo Román Zamora publicó en 1575 Repúblicas del mundo, una crónica que “describe” leyes, usos y costumbres esenciales de civilizaciones inspiradas por una "luz natural" que permitía a los hombres vivir en compañía de los demás. Inscrita en la tradición retórica española del Antiguo Régimen que juzga en lo moral los acontecimientos pasados, carece de alguna pretensión etnográfica. El rétor persuade a su interlocutor del deber de distinguir entre las cualidades y prácticas de gobierno que reproducen la ejemplaridad de aquellas dañinas. Un preliminar abordaje teórico analiza de qué manera los lectores comprendían las descripciones históricas y cómo respondían a una forma específica de entender al destinatario además del texto en sí mismo. Se analizan las condiciones comunicativas que hicieron posible la construcción de una cultura sustentada en andamiajes normativos.

Palabras clave: retórica; república; crónicas; etnografía; comunicación.

\section{[en] Rhetoric communication in 16th century' chronicles. Moral writing in Repúblicas del Mundo by Friar Jerónimo Román Zamora}

\begin{abstract}
Friar Jerónimo Román Zamora was a chronicler that published in 1575 Repúblicas del mundo. It's a chronicle about sixteen civilizations with essential laws and customs inspired by a "natural light" that allowed to coexist with other men. This chronicle is part of Spanish rhetoric tradition during Old regime because judges the historical events in agreement with Christian values. Therefore this is not an ethnographic work: its main aim was persuade to readers through morality government procedures. So Friar Jerónimo recounts a special kind of history that reprobates sinfulness. A theoretical prelim will explain how readers understood historical descriptions, at the same time I'll study which was the specific way for understanding both addressee (reader) and text (chronicle). Finally this work investigates communicative conditions that constructed the structure and functioning of social morality.
\end{abstract}

Keywords: Rhetoric; Republic; Chronicles; Ethnography; Communication.

Sumario. 1. Construir fronteras étnicas con base en la moral. 2. La escritura de la historia se corresponde con la comunicación que la hace posible. 3. Historia que persuade, edifica y deleita al mismo tiempo. 4. Una crónica más. 5. Un escrutinio alternativo. 6. Repúblicas del mundo como producción comunicacional. 7. Perennizar las diferencias: el pagano, el gentil. 8. Conclusión.

Cómo citar: Cautle Aguilar, M.S. (2019). Comunicación retórica en las crónicas del siglo xvi. Escritura normativa en las Repúblicas del mundo de Fray Jerónimo Román Zamora, en Res Publica 22.1, 65-86.

\footnotetext{
* Universidad Iberoamericana, México marcosblz1685@gmail.com
} 


\section{Construir fronteras étnicas con base en la moral.}

La instalación de los grandes Estados territoriales, administrativos y coloniales ocurrida en el siglo xvi, revela un complejo proceso de lucha por consolidar las fuerzas de conducción moral y física en toda la sociedad europea. Por un lado, tenemos la concentración estatal, y por el otro, el de la disidencia religiosa, dos movimientos cuyo cruce plantea el problema del "«cómo ser gobernado, por quién, hasta qué punto, con qué fines, mediante qué métodos»". La realidad subyacente de esos movimientos apuntaba a una preocupación de carácter "global del gobierno", la cual propició un estallamiento de mecanismos en busca de comprender las nuevas relaciones políticas que se contrajeron tras siglos de territorialización. "No hubo, por lo tanto paso del pastorado religioso a otras formas de conducta, conducción, dirección. De hecho, hubo intensificación, multiplicación, proliferación general del tema y las técnicas de la conducta. Con el siglo xvi entramos en la era de las conductas, la era de las direcciones, la era de los gobiernos"1. Los acontecimientos se subsumen en una onda que atravesaría profusamente a América de ahí en adelante, por lo que no es difícil descartar la idea de que más allá de Europa, y en especial durante el expansionismo del Quinientos, hubiera asomado algún viso de tolerancia que posibilitara la diferencia para las civilizaciones de la faz de la tierra. Insistir en la rígida épisteme conducta aceptable/conducta no aceptable, obligaba a redefinir constantemente y, por ende, a dilatar la posibilidad de aceptar los aspectos que podían hacerles iguales a su "objeto de estudio".

Tras el proceso tridentino se acentuó una política ortodoxa de enderezamiento, en la que el elemento que quedase señalado como ajeno al catolicismo - esto es, cualesquier práctica tildada de "religiosa"-, quedaría recluido indefinidamente. Fue así que se generó una práctica de recurrente renuncia a verse reflejados en aquello que se considerara "similar", toda vez que representaba una amenaza latente capaz de desbordar su institucionalidad. Lo "otro" difícilmente habría permeado en condiciones tan rígidas, porque parecía albergar una esencia atemporal anclada desde antes de la llegada de Cristo. Sólo podía haber una religión y su instrucción venía del Occidente católico. En consecuencia, el horizonte de enunciación no podía llamar de otra manera a las "semejanzas religiosas" regadas aquí y allá, más que como confabulaciones del imitador de Dios, el demonio. La República de China, descrita así por Fray Jerónimo Román Zamora (1536-1597) en sus Repúblicas del mundo, es un ejemplo pródigo en evidencias. Sorprende que la lejanía de las tierras no sea impedimento para hacer una "autopsia" de la misma, es más, podría decirse que es la condición. Fray Jerónimo Román hace uso de un criterio de verificabilidad infalible como la comparación y amplificación de los rasgos que son considerados "universales" entre los hombres, más no equivalentes. Es una descripción no neutral que esperaba "traducir al otro" de conformidad con la verdad autorizada ${ }^{2}$. Dicho de otra manera, se procuraba traducir haciendo uso del único sistema concebible, cristiano/no cristiano:

De los dioses, sacrificios templos, y sacerdotes que tiene el Reyno de la China.

M. Foucault, Seguridad, territorio, población, Curso en el College de France (1977-1978), FCE, Buenos Aires, 2006, pp. 111, 268, 271.

2 F. Hartog, "El ojo y el oído", en Historia y Grafia, 4, 1995, pp. 13-25, aquí pp. 17-18. 
De ser tan poco el trato y comercio de los estrangeros y hombres curiosos dentro del reyno de la China, ha venido que no tengamos entera notica de sus ritos en las cosas de la religión [...] Cierto es que ellos son grandes ydolatras, y gente muy supersticiosas, lo qual confirma la infinidad de simulacros y estatuas que tienen puestas en diversos lugares, a las queales hazen reverencia. En cerros y montes tienen sus oratorios, y como hermitas adonde los que camaina vean algo de sus dioses. Dad casa tiene sus ydolos o dioses la respara guarda de ella [...] Ningun conocimiento tienen de Dios verdadero, y si algo ay es rastreando y si dizen que de lo alto dependen todas las cosas criadas y la conservación y gobierno de ellas sin saber dezir en particular quien sea el autor y principio [...] No hallo sacrificios solemnes ni muertos de grandes animales, y creo que procede de que como el demonio los tiene ganados, no cura de ocuparlos en sacrificios de hombres no otras cosas crueles de que usaron otro tiempo diversas gentes ${ }^{3}$.

Al tomar como proposición los rasgos operativos con que se traducía al otro, se concluye que el a priori de observar cultos en todos lados tenga más que ver con el uso de artificios narrativos, que a cierta metodología etnográfica. El minucioso detalle realista que el cronista imprime a la construcción de la frontera étnica cristiano/ chino, exhibe la imperativa necesidad de recurrir a la "constante epistemológica" del saber histórico autorizado y a la confianza en la experiencia narrativa moral. Todo sugiere que la disposición del épísteme posibilitaba tazar de una vez por todas, la historia de un pueblo por el simple hecho de su "contumaz" desconocimiento del Dios verdadero. Bien vale la pena seguir cuestionando la intencionalidad que guardaba el acto de leer - de un modo y no de otro- los "usos y costumbres" de las repúblicas. Es muy importante interrogarse por dicho aspecto pues equivale a desmontar los juicios de valor hechos sobre las llamadas "gente con policía".

La prioridad es entender el proceso comunicativo en la escritura de la historia. Para eso abordaremos de manera sucinta un fragmento de la crónica de Fray Jerónimo Román Zamora, donde la premisa por deliberar sustenta que cualquier soporte tipográfico como las crónicas, es un producto comunicativo por lo que no es más que el reflejo de cómo su sociedad observaba el mundo. Con esta reconstrucción, que a nuestro proceder señala la intencionalidad de la crónica, proponemos observar el modo con que se observaba el mundo y sus "gentes" en el siglo xvi, claro está, según la lógica de una serie convenciones condensadas tipográficamente cuyo principio era persuadir la aceptación comunicativa a partir de lo que el receptor "espera encontrar en su interior", llámense modelos de conducta, historias ejemplares, alabanzas y descripciones moralmente aceptables. En este arte de narrar, se denominan expectativas normativas a aquellas estructuras que incrementan la oferta comunicativa controlan$d o$ el comportamiento incluso en contra de los hechos, por lo que al estabilizar una toma de decisión respecto de la realidad producida, hacen literalmente la función de guías a causa de su criterio refractario: podían ver, hacer ver y eran dichas (si no se puede ver lo se ve, tampoco puede verse lo que se dice) porque la función normativa (se cumple o no se cumple) es generalizar su sentido y validez en el tiempo a la vez que su institucionalización excluye decisiones no previas.

J. Román Zamora, Repúblicas del mundo. Divididas en tres partes, impresa en Salamanca: en casa de Ivan Fernandez, 1595, Biblioteca José Ma. Lafragua (fondo antiguo), Puebla, Puebla. Clave. 40881-41040505, TERCERA PARTE, pp. $214 \mathrm{v} .-215 \mathrm{f}$. 
La estructura comunicacional normativa de las historias para este régimen de historicidad es retórica. Con ella de igual forma se pretendía realizar la "esencia política" del hombre desarrollando y regulando sus relaciones entre otros hombres, con base en distinguir lo correcto de lo incorrecto. Se dirá por esto que la estilización normativa acontecida en la comunicación en el siglo xvi ejerce un peso portentoso que impide al lector tomar decisión alguna acerca del sentido del relato; la función de actuar como guías hacía que se sentara un juicio preconcebido más que describirlo fácticamente; en una palabra, el discurso retórico era moralizador además de cerrado y sólo pretendía que los hechos fueran asentidos o disentidos sobre la manera en que eran presentados, nunca pretendía ser abierto para que las acciones fueran susceptibles de aprendizaje cognitivo. En la retórica subyace un efecto persuasivo que cobra entero protagonismo al imponer una estimación figurativa, valiéndose tanto de la memoria como de valores morales compartidos - los topoi tan típicos de la sociedad cristiana estamental-, dos factores que fueron matriciales para la fuerza de consenso comunicacional ${ }^{4}$. Se sabe que la luz es el medio para ver las cosas, aquí la función moral del discurso retórico era el medio que hacía visible al mundo en conformidad con la verdad.

\section{La escritura de la historia se corresponde con la comunicación que la hace posible}

A través de la interpretación histórica, optamos pensar no sólo en lo lingüístico para traducir más allá del tiempo ${ }^{5}$, pues con ella también se da cuenta de la producción de distintos discursos alrededor de civilizaciones muertas (en esto coincide con la arqueología). La historia está interesada en abordar el pasado enfatizando su resguardo de la única manera en que podría constituir y organizar su relación con lo que guarda silencio. Me refiero a la escritura, una especie de obra "exorcizadora" de la muerte que pone a la vista los restos de algo que ya no es un verdadero cuerpo, pero al que paradójicamente es necesario construirle una "tumba". Con la escritura del pasado

$4 \quad$ El fenómeno contemporáneo de la cultura de masas tiene todas las cartas para apelar contra el derecho de exclusividad de las sociedades de soberanía, al respecto de la fuerza de consenso de una comunicación. los efectos del poder difusivo de las tecnologías de la información hablan por sí mismos. Ciertamente los consenso pueden no ser exclusivos de un régimen de historicidad, pero su forma de materializarse sí es única. En la cultura de masas la tendenciosa información de contravenciones de normas, por ejemplo, potencian la afección colectiva y la indignación, y todo porque no se conoce el contexto total de la desviación de la norma ni cómo es que alguien se comportaría de encontrarse en esa misma situación de flagrancia de la norma. Niklas Luhmann estudió las consecuencias de la "pluralistic ignorance" o "el desconocimiento de la normalidad de la desviación": "la falta es la que hace surgir verdaderamente la norma, ya que en la masa de normas vigentes, la norma sólo es «válida» [...] Esto ya no aparece en la forma llena de riesgos de la predicación o de la indoctrinación (que en la actualidad, más bien haría surgir la contra-socialización), sino acontece bajo la forma inocua de la mera información, lo que permite a cada quien sacar la conclusión: ¡eso no debe ser!”, N. Luhmann, La realidad de los medios de masas, tr. Javier Torres Nafarrete, Barcelona, UIA/Anthropos, 2000, p. 47.

5 "En ausencia de la interpretación, en el sentido múltiple y sin embargo aceptado del término, no habría cultura: sólo un silencio sin eco a nuestras espaldas. En una palabra, la existencia del arte y de la literatura, la realidad de la historia sentida y vivida en el seno de una comunidad, dependen de un proceso continuo, aunque a menudo inconsciente, de traducción interna. No es exagerado decir que poseemos civilización porque hemos aprendido a traducir más allá del tiempo", G. Steiner, Después de Babel: aspectos del lenguaje y la traducción, trad. de Adolfo Castañón, México, FCE, 1980, p. 48. 
se da un soporte material a algo que en otro momento había quedado en un registro sin voz. Dicho con precisión, el vínculo entre producción de cultura y exhumación consistiría en dejar hablar a los muertos, en no dejar de interpelarlos. Es el caso de su recorrido escriturístico, que va dejando una estela de convenciones plasmadas sobre el papel como reflejo del saber de una sociedad. Éstas interpretan selectivamente las fronteras que el tiempo estratifica pero que es necesario sacar de la tierra (al igual que todo desentierro del que no se puede recuperar todo el cuerpo, tampoco se puede recordar todo, así que siempre hay cortes y omisiones). En otras palabras, escribir la historia es un ejercicio de narración para conceder un cuerpo a los fantasmas del pasado resonante, por lo mismo esta operación se propone traducir, hacer legible y finalmente exponer el "cadáver mudo", para luego volver a enterrarlo: "[...] la reconducción del «muerto» o del pasado a un lugar simbólico -afirma Michel de Certeau- se articula aquí con el trabajo que tiene por fin crear en el presente un lugar (pasado o futuro) que debe llenarse, un «deber» que hay que cumplir [con el hacer historia]". Con razón Certeau afirmaba que "El lenguaje permite a una práctica [semantizada] situarse con respecto a su otro, el pasado"6. Y en otra parte: "La historia hace hablar al cuerpo que calla. Supone un descasamiento entre capacidad silenciosa de la «realidad» que desea expresar y el lugar donde produce su discurso, protegida por la distancia que la separa de su objeto (Gegen-stand $)^{7}$.

La dirección de ésta postura apunta al presupuesto de nuestro abordaje metodológico: si hacer la historia conlleva "las relaciones que un cuerpo social mantiene con su lenguaje" dice Certeau ${ }^{8}$, entonces darse un presente gracias a la escritura ha de ser una empresa siempre relativa a las operaciones que la constituyeron como tal. De ahí que cada sociedad determine las condiciones que posibilitan entender los acontecimientos de una forma y no de otra. Digamos que cada tiempo es una realidad que se corresponde con el utillaje cultural hasta allí producido, y que sin éste no se podría acceder a esa realidad. Vista así, la escritura de la historia toma un giro deliberadamente social que no puede limitarse al individuo que la elabora. No es en la conciencia de un sujeto, sino en la comunicación que la sociedad comparte (patrimonio conceptual) donde el mundo es observado según un orden de realidad específico. Comprender los relatos es el resultado del enlace operativo puesto en marcha con cada comunicación ${ }^{9}$. ¿Qué quiero decir con esto? Que los textos son la internalización de reglas asumidas entre los distintos miembros que conforman una sociedad. La construcción de una realidad es precisamente una cuestión que pende más de la posibilidad de recibir un mensaje que de la emisión de él: se puede o no estar de acuerdo con lo notificado, pero no poder comprender lo que el otro dice le deja aislado y en el nivel de su conciencia. Los hombres necesitan relacionarse para comprender la realidad, por eso su mejor forma de acceder está es reproducir las convenciones que se desarrollan durante la comunicación.

$6 \quad$ M. de Certeau, La escritura de la historia, trad. Jorge López Moctezuma, $1^{\mathrm{a}}$ ed., en español, 1999, $2^{\mathrm{a}}$. reimpresión, Ciudad de México, Universidad Iberoamericana, 2006, p. 117.

Ibidem, pp. 16-17.

Ibidem, p. 118.

9 El mérito de la tematización en torno a la comunicación y las crónicas del siglo Xvi según Niklas Luhmann, pertenece a Alfonso Mendiola. Yo soy el responsable de la interpretación que hago de su investigación al respecto de Fray Jerónimo Román Zamora. cf. A. Mendiola, Retórica, comunicación y realidad: la construcción retórica de las batalla en las crónicas de la conquista, Ciudad de México, Universidad Iberoamericana, 2003. 


\section{Historia que persuade, edifica y deleita al mismo tiempo.}

Entre las amplias posibilidades gestadas por la escritura de la historia en Occidente hubo una que brilló estratégicamente durante el periodo de las sociedades de soberanía. Hasta los albores del siglo xvii, el género histórico que predominó en el mundo veteroeuropeo fue la crónica, especialmente importante para el mundo hispánico. Tal empresa requería del uso de la máxima institución comunicativa que prodigaba prestigio a la punta de la pirámide social: la retórica en su género epidíctico. Aristóteles dice que a éste género le corresponden "[...] la virtud y el vicio y de lo bello y lo vergonzoso, pues éstos son los objetivos (que persigue) el que elogia y el que censura". Al hacerlo "pone ante los ojos" la grandeza de una virtud, expone cuán grande puede ser el vituperio por las faltas, pero también "la facultad de producir y conservar los bienes y, también, la facultad de procurar muchos y grandes servicios de todas clases y en todos los casos". El Estagirita asume la virtud como "la capacidad de «acarrear bienes» y ser «de utilidad para los otros»", porque quiere sentar las bases en torno a la conducta humana manifiestamente libre: "ya que (los que practican esta virtud [de la libertad]) son desprendidos y no rivalizan por el dinero, que es lo que más desean todos". Se procede a persuadir con evidencias para que los actos justos, valientes, moderados, magnificos, magnánimos, libres, sensatos y sabios, queden preservados en la memoria y eduquen a otros hombres con aspiraciones bellas y virtuosas. Por eso es importante "intensificar la importancia cualitativa de los hechos" aprovechándose "en cada caso de estas semejanzas [lugares comunes] siempre en el sentido de lo mejor"10.

Un elemento intrínseco al panegírico o elogio son las aserciones metafóricas, y para mostrar "lo ejemplar a que debe ser referido todo juicio acerca de hombres, acciones o situaciones", antes es necesario una lógica enteramente figurativa. ¿En qué consiste y porqué su impacto en la cultura escrita de tantos siglos? La lógica de imágenes reside sobre la base de una acto inmediato de visión, "la de mostrar algo y simultáneamente la de referir a otra cosa, porque es de esta manera como los fenómenos alcanzan un significado". Así para el panegírico la realidad es concreta por ser el resultado de "conferir significados a los fenómenos con respecto a su connotación humana. En otras palabras, «hallar» el punto de comparación y de semejanza entre la realidad y nosotros mismos como seres humanos, equivale a hallar la relación requerida para satisfacer nuestras necesidades materiales y espirituales". Visto de este modo, semejante autorrealización conlleva a la "humanización de la naturaleza" pues, dados los cambiantes estados en que el hombre se encuentra (apariencias), sólo es válido aquello que le permita desarrollar su existencia. Son sus actividades imaginativas y metafóricas la base para adecuar la realidad a tales necesidades. Ernesto Grassi señala que "este doble modo de «comunicar» cosas, este trabajo, es el supuesto para la fundación de instituciones sociales y políticas". Lo que no ocurriría así de tratar la razón de las cosas, razones vinculadas a un único tiempo (lógica racional) que garantiza la objetividad de las afirmaciones a la hora de derivar una proposición de sus premisas.

En semejante lenguaje [imaginativo] no nos enfrentamos jamás con seres humanos abstractos, sino más bien con seres que se encuentran, como nosotros mismos,

10 Aristóteles, Retórica, Introducción, traducción y notas por Quintín Racionero, Madrid, Biblioteca Clásica Gredos, 1990, pp. 240-254. 
en relaciones temporales y espaciales a través del trabajo. Los conceptos mediante los cuales llegamos a entender y a "aprehender" cada situación particular proceden de nuestras capacidades ingeniosas, metafóricas y fantásticas, que confieren significados en las situaciones concretas con que nos enfrentamos ${ }^{11}$.

No es extraño que bajo el amparo del ars narrandi se hicieran extensos compendios de acontecimientos estilizados metafóricamente, con la finalidad exclusiva de enfatizar las cualidades morales de sus actores por encima de los hechos en sí mismos. "Para el siglo xvi ya no se realizan juicios legales a la manera antigua; por ello la narración se tematiza con respecto al género epidíctico. Además, los primeros manuales de cómo escribir historia son de esa época, y el género histórico se caracteriza como una variante del epidíctico. La historia es vista como un relato para juzgar en lo moral las acciones pasadas"12. Lo fáctico quedaba supeditado a lo ejemplar. Aquí el arte de pensar y participar en las relaciones de poder dependía de hablar elocuentemente. Fue entonces que se construyó una cultura del deber ser de predominante verticalidad estamental; allí las jerarquías se encontraban destinadas a un anquilosamiento, cuya salida era sólo hacia arriba. La aristocracia supo aprovechar la prodigiosa ventaja del derecho de nacimiento valiéndose de fuentes que ensanchaban sus intereses. En tanto discurso centrípeto, la comunicación retórica motivaba su comprensión autorreproduciendo valores que pusieran en balanza todo aquello que resultase esencial para la moral institucional, o bien, que tuviera que ver con comportamientos semejantes. La concepción circular del tiempo no dejaba a dudas de que aquél que no conociera los errores del pasado, estaría condenado a repetirlos. Cuán conveniente se había vuelto obtener provecho de situaciones que antaño hubieran afianzado altas posiciones y reconocimientos.

La historiografía moderna tiene el mérito de haber trazado una distinción que nos permite pasar de un pasado pensado no como algo dado (objeto), a otro que es producto de una construcción, donde "la realidad aparece como una construcción que se realiza por medio de una operación peculiar: la observación", y esta operación que "realiza la sociedad para observar tiene la forma de comunicación"13. En el complejo proceso del desarrollo de su cientificidad hubo otras lecturas históricas que permitían a sus sociedades recrearse en el pasado, lo que así sucedió con la observación elaborada sobre el modelo del clero regular de los monasterios (s. xiv-xv), discurso inevitablemente marcado por una teología muy estricta y de un coherente desplazamiento que asumía su centralidad en la teofanía ${ }^{14}$. Ese era el caso de la historiografía cristiana, cuya evidente raíz medieval jamás habría

11 E. Grassi, "Retórica y filosofía: la tradición humanística (segunda y última parte)", en Revista de Filosofia, volumen 17, Núm. 1, 1979, pp. 25-46, aquí pp. 44-45, consultado el 19 de diciembre de 2018 en URL : HTTPS://REVISTAFILOSOFIA.UCHILE.CL/INDEX.PHP/RDF/ARTICLE/VIEW/44410/46416

12 A. Mendiola, "La amplificatio en el género epidíctico del siglo xvi”, en Historia y Grafía, 43, 2014, pp. 103125 , aquí p. 104.

13 " $[\ldots]$ dentro de esta forma de observación, que es propia de la sociedad, existen algunas con pretensiones de validez (las comunicaciones científicas). En el caso de las ciencias modernas, como la historia, esta comunicación se da a través de un medio de difusión particular: la imprenta", A. Mendiola, "El giro historiográfico: la observación de observaciones del pasado", en Historia y Grafia, 15, 2000, pp. 509-537, aquí pp. 515-517.

14 F. Dosse, "El acontecimiento histórico entre esfinge y fénix", en Historia y Grafía, 41, 2013, pp. 13-42, aquí p. 37. 
concebido la idea de un mundo ajeno a la religiosidad. Todo tenía que ver con todo: en un universo mental en el que todos los ámbitos de las relaciones humanas tenían que ver con un centro, la teología, y los cambios sociales y políticos no podían sustraerse, o mejor dicho, pensarse por separado, las funciones reales y eclesiásticas se legitimaban recíprocamente ${ }^{15}$. La escritura de la historia hasta el Antiguo Régimen, valoraba la congruencia moral en continuidad con el eschaton y no la coherencia innovadora. A este estrato del tiempo tan prolongado, que llevó a normar la cotidianidad de la experiencia haciendo desplazar las expectativas sobre sí mismas una y otra vez, corresponde un uso temporal imitativo del tipo cristo-céntrico. El principio de imitar a Cristo se resume en que la experiencia auténticamente histórica aprende que su alma purgante le espera la redención; pero que al conocimiento de sí vendría la plenitud de morir para vivir. En el horizonte de esperanza cristiano se era "receptáculo de múltiples experiencias ajenas de las que [podíamos] apropiarnos"16. Quedar libre de los errores del pasado aducía principalmente un cuerpo político integrador con entera capacidad de conservar el orden. Hacer historia exponía sistemáticamente la consistencia de un mundo eterno por y para sí mismo.

De acuerdo con la métrica escriturística estamental, me he propuesto abordar una crónica del siglo xvi con la intención de comprender el tipo de discurso que sirvió al autor en su proceso de descripción de culturas a las que denominó como repúblicas. Esto significa tomar una apreciación alterna de las crónicas que consiste en dejar de calificarlas como documentos puramente proyectivos que retratan la realidad por encima de su contexto de emisión (fuentes). Es el porqué de entender este texto como una "comunicación", que si bien es cierto el lenguaje es duplicado por la escritura en un sistema de signos disponible fuera de todo contexto interactivo, en realidad "El lenguaje no es perceptible porque sólo es un medio, las perceptibles - gracias a él- son las conversaciones" ${ }^{17}$. Con esto se intenta decir que el tratamiento historiográfico por emprender responde a una forma específica de entender al destinatario además del texto mismo. En suma, se trata de conocer el lugar donde se produce el discurso, que no es otra cosa que la reproducción de condiciones que hicieron posible la comprensión de la crónica. En la labor de hacer legibles los rastros que el sustrato físico Repúblicas del mundo interpela a la historia contemporánea, decidí concentrarme en entender el espacio desde el que opera el interlocutor (lector de la obra), lo que implica dar paso al lugar institucional en que la unidad emisor-destinatario está inscrita. Me limitaré a exponer parte de éstas cuestiones que he estudiado extensamente en otro lugar ${ }^{18}$. Por ahora sin más atenderé el propósito que esta crónica perseguía al ordenar a ciertas civiliza-

15 N. Durán, "De la evangelización de los mendicantes a la «rectificación» jesuita de José de Acosta", en P. Chinchilla y A. Romano (eds.), Escrituras de la Modernidad. Los jesuitas entre cultura escrita y cultura cientifica, Ciudad de México, Universidad Iberoamericana, 2008, pp. 21-52, aquí pp. 38-39,

16 [...] su unidad era - como la existencia del Imperio — garantía del orden hasta el fin del mundo. De este modo, el futuro, como posible fin del mundo, ha sido incluido en el tiempo como constitutivo para la Iglesia y no se encuentra, en un sentido lineal, al final del tiempo: más bien, se puede concebir el final del tiempo solo porque ésta conservado desde siempre en la Iglesia. Y así la historia de la Iglesia es la historia de la salvación". R. Koselleck, Futuro pasado. Para una semántica de los tiempos históricos, Barcelona, Paidós, 1993, pp. $26,42$.

17 A. Mendiola, Retórica, comunicación y realidad, op. cit., p. 98.

18 M. S. Cuautle Aguilar, Repúblicas del mundo de Fray Jerónimo Román Zamora. "Gentes con policía” e historia de un programa retórico en una crónica del siglo xvi. Tesis Doctoral sustentada el 1 noviembre de 2017, Acervo Universidad Iberoamericana, Ciudad de México. 
ciones por su grado de "república", dicho de otra forma, por su capacidad natural de perpetuar la vida en común a través de leyes que les permitían vivir en compañía de los demás (aquí no describiré las repúblicas ordenadas por el cronista). Al resultado positivo y valorador de arbitrar el buen gobierno es lo que en las $R e$ públicas del mundo se entenderá como "policía". Es precisamente esta condición que alumbraba a todos los hombres para alcanzar su debido lugar en la historia, lo que inclinaba a los pueblos a estar organizados bajo costumbres acordes a su estado natural, signo indeleble de un conocimiento mínimo de Dios... más de las veces nublado. En relación al tema de la autoría, aquí su relevancia no estriba en los elementos biográficos que pudieran obtenerse, antes bien es la función que desempeña su inefable individualidad en la arquitectura global del género epidíctico.

\section{Una crónica más}

Fue una llamada de atención descubrir entre la vasta herencia de cronistas indianos del Quinientos, la mención de un hombre que había sido presa de la Inquisición tras la publicación de un interesante libro dividido en dos volúmenes, en el cual se describían las leyes, usos y costumbres de distintas sociedades ${ }^{19}$. Quizá sea una de las primeras historias abocadas enteramente a caracterizar las formas de gobierno allende a España. El motivo fue la escandalosa mención hecha contra los responsables de la caída del indio americano: ahí se acusa a los conquistadores Cortés y Pizarro de las desgracias que contraería la Corona española por su destructivo apoderamiento territorial. Un análisis más detenido de este texto denota que su expurgación no fue tan estricta, sobre todo cuando se piensa que este reproche se reduce a porciones de párrafos ubicados en dos capítulos, mismos que pertenecen a una de las dieciséis repúblicas que conforman el mundo del cronista. La obra, decíamos antes, llevaba por nombre Repúblicas del mundo y perteneció al rétor logroñés Fray Jerónimo Román Zamora de la orden de los agustinos. Editada primero en 1575, contaba hasta ese momento con nueve republicas (la última dividida en tres); veinte años después, añadirá otras cinco que darán con el cuerpo final de la obra ${ }^{20}$. En el tránsito a 1595 llevará a cabo otras obras de importancia, pero quizás ninguna tan vasta como ésta ${ }^{21}$.

La citada acusación que le provocó el atajo inquisidor, se encuentra en la república que trata propiamente los acontecimientos del Nuevo Mundo, la República de los Indios Occidentales. Su censura por los agravios se limita principalmente al de "poner en duda el Señorio" de España. Otros "inconvenientes" que no se mencionan en esta orden, muestran, según la presente investigación, mayores censuras sobre la república que abre toda la crónica, la República hebrea. El fuerte rechazo a cualquier expresión "judaizante" que todo el siglo español respiró, sin duda responden a este

19 El documento de censura está reproducido en J. Torre Revello, El libro, la imprenta y el periodismo en América durante la dominación española, Ciudad de México, UNAM, Instituto de Investigaciones Bibliográficas, no. 74, 1991, p. xxv.

20 Para los fines del trabajo, hemos utilizado la versión impresa en Salamanca de 1595 y dividida en tres partes.

21 En la edición de 1897 hecha por el primer editor Pedro Víndel, se cita toda una veintena de obras. P. Vindel, Colección de libros viejos, raros o curiosos que tratan de América. Tomo xiv. Repúblicas de Indias, idolatrías y gobierno en México y Perú antes de la Conquista. Fielmente reimpresas, según la edición de 1575, con una addenda de las noticias que hay en la Crónica, del mismo autor, impresa en 1569, Madrid, 1897, Victoriano Suárez, Editor. Preciados, 48. 
acto. De cualquier forma sólo se redujo una pequeña porción de capítulos del primer volumen en el que se ubica dicha república, aspecto que puede comprobarse contrastando los capítulos de ésta con la segunda edición donde uno puede percatarse de los títulos que todavía permanecen, a modo de un rastro dejado por los capítulos faltantes en la versión más reciente. Lo importante no es que Fray Jerónimo Román haya hecho una que otra mención de rituales y otras costumbres secretas de la república hebrea, llegando a compararla con el sufrimiento que los indios a causa de su destierro; incluso creemos que tampoco la fricción generada por la acusación a los conquistadores haya sido la causa. Al parecer no fue este su detonante exclusivo, aunque sí pudo actuar como cargo suficiente ${ }^{22}$. Sobre todo porque el cronista se las ingenió para volver a publicarla y, curiosamente, ya sin trabas mayores. Obtuvo el permiso de imprimatur bajo las mismas condicionantes estrictas ocurridas dos décadas atrás. A pesar de la reprimenda que le llevó a recortar su obra, Fray Jerónimo Román se propuso obrar en sentido contrario, así repuso los faltantes con nueva información en una cantidad considerable que le permitió adicionar un tercer volumen, llegando de ese modo a un número promedio de mil doscientos folios, mientras que la primera era de alrededor de novecientos.

Para la edición de 1575 que todavía se encontraba en dos volúmenes, presenta xxvii libros que se reparten en " 2 de la república hebrea, 7 para la cristiana, 1 para la septentrional -Suecia y Moscú-, 1 para la veneciana, 1 para la genovesa, 1 para las repúblicas diversas (Inglaterra, Luca, los Sguizaros -Suizos-, y la república Ragugina). Ya en el vol. 1 la república gentílica tiene 10 volúmenes, 3 la de los Indios Occidentales y uno para las de turcos, tunecinos y Fez, respectivamente"23. La comparación con la versión de 1595 hecha por Rolena Adorno resulta de esta manera:

Conforman la Parte Uno la República hebrea y la República christiana; la Parte Dos la República gentílica y la Parte Tres un gran número de «repúblicas» (Moscovia, Venecia, Génova, Etiopía, Inglaterra, Luca, China, Fez y los turcos), a las que se da un tratamiento menor. La República de los Indios occidentales es la que recibe, por lejos, el tratamiento más largo en la Parte Tres, ocupando alrededor de setenta folios del volumen ${ }^{24}$.

Un complejo contexto represor hacia las décadas de los sesenta y setenta del siglo xvi cayó como una lápida sobre las obras que trataban del tema indiano, mandando que se "buscaran materiales de esa índole en los archivos, oficinas y escritores locales"25. Es probable que los cargos inquisitoriales sobre las Repúblicas respondieran a un problema asociado con el "secreto de estado" más que con el de un examinador "intelectual" al margen del poder. De hecho fue la presencia de uno de los más connotados cronistas el que había iniciado la desaprobación de su obra, me refiero al Pa-

22 El análisis comparativo es exclusivo de la especialista Rolena Adorno, "La censura y su evasión. Jerónimo Román y Bartolomé de las Casas", trad. Cristina Carbó, en Estudios de Cultura Náhuatl. Anuario de investigaciones históricas de la UNAM, Editor Miguel León-Portilla, 23, 1993, pp. 263-296.

23 A. J. Sánchez Ferra, “El logroñés Jerónimo Román y su obra sobre las Repúblicas del Mundo”, en Cuadernos de investigación. Historia, 10, 1984, pp. 307-315, aquí p. 314.

24 R. Adorno, "La censura y su evasión", op. cit., pp. 264-265. Por su importancia, realicé la transcripción completa de las Repúblicas de los Indos occidentales.

25 A. Brendecke, Imperio e información. Funciones del saber en el dominio colonial español, trad. Griselda Marísco, Madrid, Ed. Iberoamérica-Vervuert, 2012, pp. 426-427. 
dre Las Casas, de quien tomará por primera vez en ese mismo siglo una buena parte de su magna obra la Apologética historia sumaria, inédita hasta entonces. Como su "editor indirecto" (Fray Jerónimo desiste de nombrarlo y deja un espacio en blanco), sacó provecho de sus descripciones "favorecedoras" de los indios así como de las condiciones para una buena república. Lo que hay que señalar de esta apropiación, más no plagio ${ }^{26}$, es el hecho de que tal como ocurrió con el dominico, Fray Jerónimo también reivindica los valores de la élite: "Cuando Fray Bartolomé de Las Casa escribe impugnando al monarca, está respetando una norma, no tiene nada de extraordinario ni de rato, es una regla moral que expresa que el monarca es responsable ante Dios de lo que haga su pueblo, por lo tanto se le debe informar y exigir"27.

\section{Un escrutinio alternativo}

Con sólo partir de la mentalidad del discurso de la época vemos que los cronistas actuaban exigiendo decisiones políticas que estuvieran a la altura de su valoración moral, de tal forma que sus narraciones, por breves o extensos que fueran sus vituperios, en realidad había un recordatorio normativo que posibilitaba tal demanda, sin contar las intenciones que llevaban al uso económico de tales obras. Los cronistas y la corona amalgamaron un tipo de historia que subrayaba una "política de la reputación" que, independientemente de su contenido, camuflaban intereses. El carácter oficial de aquellas, "ya fuera en forma de historia pro persona o historia por patria, extraía buena parte de su energía e inspiración [...] de los esfuerzos por parte de los monarcas de mejorar su imagen y, en última instancia, de incrementar su poder por diversos medios" ${ }^{\prime 28}$. Insertos en el aparato estatal, los cronistas se convertían literalmente en funcionarios de la administración; la idea era "aparentar justicia distributiva manteniendo abiertos los canales de comunicación y las correspondientes oportunidades de participación", de esta forma "las partes no sólo se pusieron en movimiento, reclamaron equidistancia del poder y equidad de acceso a él" ${ }^{29}$. La retórica se había convertido en el instrumento ideal de su oficio.

Las concesiones que los cronistas hacían de su reflexión histórica en las condiciones políticas de entonces, eran producto de procedimientos con un fin superior, y la historia "era el mejor modo para la formación política, en el doble plano de

26 Un profuso encomio por el prestigio se encontraba por encima de la innovación. La idea superviviente de una herencia común a todos a través de textos clásicos, fue durante siglos un esquema coercitivo que "culturalmente se consideró una actividad de descubrimiento, preservación, ordenación y aclaración de un saber que se consideraba esencialmente completo, a la luz de una única hermenéutica (la fe cristiana) ya revelada”. El intenso ambiente de intertextualidad se denota allí. En uno y otro lado, hasta muy entrado el siglo xvii, se desenvuelven series de escolios o síntesis, compilaciones, extracciones y paráfrasis de textos canónicos. El "patrimonio público" es un espacio que fomenta la instrucción, pero que condena la intensión de engañar o voluntas fallendi de los escritores. Está la poderosa resonancia de "una producción textual preconizada por una tradición literaria omnívora y omnipresente”. K. Perromat Augustín, El plagio en las literaturas hispánicas: Historia, Teoría y Práctica. Literature. Université Paris-Sorbonne - Paris IV, 2010. https://tel.archives-ouvertes.fr/tel-00992391 Submitted on 17 May 2014; tomado el 18 de octubre de 2015 en url:

https://hal.inria.fr/file/index/docid/992391/filename/These_LePlagiat_KevinPERROMAT.pdf. pp, 58, 62.

27 A. Mendiola, Retórica, comunicación y realidad, op. cit., p. 88.

28 R. L. Kagan, Los Cronistas y la Corona. La política de la Historia de España en las Edades Media y Moderna, Madrid, Marcial Pons, 2010, p. 349.

29 A. Brendecke, Imperio e información, op. cit., pp. 80-81. El subrayado es mío. 
la conducta personal y colectiva"30. Los afanes por resaltar la unidad de España, y su superioridad sobre otras naciones, requirieron de un arsenal humano prolijo de narraciones de acontecimientos listos para atender las expectativas del grupo al que iban dirigidas. Desde la Baja Edad Media, se tenía entendido que los títulos Annales, crónicas, historias, gesta eran un sinónimo para anunciar una obra de contenido histórico:

Se recreaba - o mejor inventaba- la historia intercalando narraciones fabuladas junto a mitos, tradiciones, ritos y otros acontecimientos históricos, buscando en la invención del pasado la justificación del presente, cuando no la construcción de la propia identidad nacional recurriendo a los mitos fundacionales. La crónica, en suma, vehiculaba la propaganda del propio estado hacia las élites aristocráticas que, a su vez, lo transmitían de forma piramidal al resto de la sociedad ${ }^{31}$.

Fray Jerónimo fue ante todo un rétor que comunicó ejemplos y modelos de conducta relacionados con el deber de la cosa pública, es decir, hacer el gobierno. "Ya fuera en forma de historia pro persona o historia por patria, extraía buena parte de su energía e inspiración [...] de los esfuerzos por parte de los monarcas de mejorar su imagen y, en última instancia, de incrementar su poder por diversos medios" $"$. El agustino abordó una extensísima historia desde tiempos bíblicos, pasado por la histórica eclesiástica del poder de la Iglesia, hasta encontrarse con civilizaciones contemporáneas ocupadas en resguardar el orden de sus estamentos, o lo que es igual, en perpetuar la vida en común que es vivir en compañía de los demás. Por esta causa recurre a hacer la historia de otras civilizaciones en las que también se habían desarrollado usos efectivos de gobierno, especialmente porque ponían en marcha pautas normativas extraídas de buenas costumbres y el rechazo de las perjudiciales. Para Fray Jerónimo, una capacidad inherente que los hombres llevaban impresa en sus almas, era la responsable de que los deberes en la comunidad de los estamentos pudieran llevarse a efecto. Podría decirse que sin esta "lumbre natural", la condición de república ni siquiera podría concebirse, toda vez que de ella emanan las facultades del derecho natural y positivo que regían a una sociedad auténticamente "humana". Esto supone que la habitación geográfica y la extensión relativa de los estamentos, las costumbres con policía inspiradas por el razonamiento, todas ellas bajo el mando de un solo regente, creaban a una república. Repúblicas, dijo el cronista respecto del título de su trabajo, fue lo mismo que llamarlo "libro de la cosa pública". Por grande que fuera la diversidad de funciones, la gente vivía con elementos constitutivos esenciales además de ser extensibles a todo mundo.

En las Repúblicas están [...] todas las cosas que el mundo halló para su contento [...] porque como la cosa pública se compone de diversas cosas, así divinas, como humanas, y en ella hay policía, y las artes en su perfección con todo lo necesario, hay justicia, castigos, y premios, para los buenos y malos hay hombres principales

30 E. García Hernán, "La España de los cronistas reales en los siglos XVI y XVII", en Norba, Revista de historia 19, 2006, pp. 125-150, aquí p. 127.

31 J. F. Utrilla, "Historia y ficción en las crónicas aragonesas. Cronistas y propaganda política en la Edad Media," en Aragón en la Edad Media, 18, 2004, pp. 83-116, aquí p. 83.

32 R. Kagan, Los Cronistas y la Corona, op. cit., p. 349. 
de todos los estados para en paz y en guerra, y otras muchas cosas necesarios para la vida humana ${ }^{33}$.

Al hablar de república nuestro cronista no apela por algún sistema de gobierno "independiente", mucho menos a manos del pueblo. Son estrictamente hablando gobiernos estratificados de un fuerte orden tradicional, compuesto de aristócratas, milicia, sacerdotes, comerciantes, campesinos; en resumen, de hombres que, como resultado del fijismo de su naturaleza, son lo que hacen pero no forzosamente lo que deben. Y es que como parte de la varietas rerum, además del condicionamiento que la historia provocaba, todos hombres podían desarrollar mayor o menor grado de lucidez, incluso hasta perderla. El único estamento capaz de cultivar esta facultad era la aristocracia, por consecuencia, al ser el orden máximo del vértice, le compelía a ella proporcionar la salud de la república. Fray Jerónimo apela en entender la buena gobernación como resultado de una fuerza coercitiva que tiene su origen en primum praeceptum de la ley natural ${ }^{34}$.

Lo que en esa época se entendía por república, "el ayuntamiento de los distintos órdenes y "suertes del vivir»" 35 , hace hincapié en la existencia de una potestad normativa o administrativa entre los hombres. Vivir en comunidad se vuelve una gestión natural que persigue un fin natural. Por peculiar que parezca, dada la propensión al pecado que tienen los hombres, resultaba imperativo proceder con las alternativas que su razonamiento les podía proveer. La composición de las causas primera y segunda era respectivamente el marco general que la ley natural o eterna proveía a la ley humana o positiva. Mientras que Dios establecía con su ley las líneas convenientes para alcanzar el fin natural de las cosas, la justa acción humana cubriría los aspectos singulares de la vida cotidiana. Et certe opera Deus facit mediantibus causis secundis, es decir, Dios opera a través de las causas segundas, era una máxima que refería las precisiones que el hombre ha de tomar en su libre albedrío, por convenir y regular eficazmente todos los aspectos de su vida ${ }^{36}$. La razón es clara:

33 J. Román Zamora, Repúblicas del mundo, Prólogos a la Primera y Segunda partes, p. 156v.

34 "Cuanto mayor sea el número de etapas que se interponen entre el acto cognitivo original y la codificación de la ley, habrá más posibles causas de error y, por lo tanto, será menor la fuerza coercitiva del mandato final. Pero todas las leyes y normas humanas, si son justas, tienen un origen discernible en algún primum praeceptum de la ley natural. Esto es válido no sólo para leyes obvias, como las que condenan el crimen, el robo o el adulterio, sino también para el simple comportamiento diario: lo que un hombre come, las formas de tratamiento para otros miembros de su grupo, las ropas que lleva, etcétera. Cada aspecto del comportamiento humano puede juzgarse natural o antinatural $-\mathrm{y}$ como el descubrimiento de los segundos principios depende de la deducción, también racional o irracional - por abstracción de algún primer principio muy general", A. Pagden, La caída del hombre natural: el indio americano y los origenes de la etnología comparativa, Madrid, Alianza Editorial, 1988 , p. 95.

35 A la noción de república "se sobrepondrá posteriormente el Estado en la literatura de la razón de Estado a partir de la última década del xvi (Estado, cabeza de la república como cuerpo, sustitución analógica del cuerpo místico de Cristo - Cristo, cabeza del cuerpo que forman los justos-, que ha servido de base, consciente o inconscientemente, a toda concepción moderna del sujeto histórico colectivo, revolucionario o no, y a las distintas dialécticas entre dirección y obediencia). El número de órdenes había quedado normativamente definido para nosotros en las Partidas: Oradores, labradores y defensores". L. de León, Tratado sobre la gracia y la justificación, Opera xiii, Introducción, transcripción, versión y notas de José Manuel Díaz Martín, Texto bilingüe, Madrid, ediciones escurialenses, real monasterio de el escorial, 2008, pp. 88-89.

36 " [...] lo que en la ley de la naturaleza se prescribe indeterminadamente, por una cierta motivación // general y difusa, se precise gracias a la ley humana; por ejemplo, la ley natural ordena que demos culto y veneremos a Dios con sacrificios, y que con cierto honor y culto nos entreguemos a Él. Pero, en cambio, no determina la ley 
"Éste [el hombre] vive en la historia. No vive al nivel de la ley eterna. Participa en ella de una forma imperfecta, condicionado por la historia y dañado por el pecado"37. Por ejemplo, Fray Jerónimo aconseja a los príncipes fingir indiferencia y "los vicios que con gran dificultad se pueden evitar, necesario es que se pasen debajo de disimulación, ansí como el fornicar soltero con soltera, hablar osiosamente y tener pensamientos malos"38. Lo que al logroñés importaba era evidenciar que el poder del rey (a pasar de todo, temporal) es incapaz de resolver con leyes humanas el problema que implica controlar el pensamiento y la conducta; disimular no es por mera indiferencia, sino que el remedio para los pecados de la naturaleza caída pertenecen al único soberano universal.

La tesis de que las civilizaciones deliberadamente se habían inclinado a vivir en compañía de otros como evidencia de tener policía, y desde luego conocimiento de Dios por ser éste el autor de la vida en sociedad, es la explicación de porqué Fray Jerónimo amplificará su narración a partir de comportamientos que consideraba "semejantes" en otras sociedades ${ }^{39}$. Sin embargo, se puede aseverar que este procedimiento fue un recurso para construir (invención) fronteras étnicas impermeables al cristianismo. Bajo esta condición, no hay oportunidad para pensar que Fray Jerónimo Román llegara a cultivar algún sentido etnográfico de la otredad. Cuando la censura actuó no fue pensando en que él estaba violando una regla de representación de las civilizaciones, pero se sabía claramente que sus descripciones retóricas cumplían la función de transmitir enseñanzas morales cristianas, así que lo más probable es que el tema de las Indias occidentales se revestía de un problema muy distinto: el aparato burocrático pretendía mantener bajo control la información decisiva del poder monárquico, esto es, atando a los actores y los procesos políticos bajo pautas normativas, cuya implicación fue limitar el margen de acción de las distinta instancias que podía apelar a la vida indirecta de la obligación de informar. Los cronistas del siglo colonizador fueron agentes con filiaciones políticas y propósitos económicos derivados de acción social; su movilidad en las cortes, la influencia y obligación de informar a las autoridades. Todos estos escritos estuvieron orientados a la reproducción del sistema retórico aristocrático, una operación necesaria que les proporcionaría el sustento y lugar en su estamento. Ya fueran frailes o encomenderos, cada uno utilizó su destreza retórica para movilizar sus intenciones, por lo que cada cronista narraba

natural de qué modo o mediante qué ofrendas hay que hacerlo; luego, a fin de precisarlas y establecerlas pormenorizadamente, fue necesaria la ley humana". L. de León, De Legibus. Tratado sobre la ley, José Barrientos y Emiliano Fernández (eds.), edición bilingüe latín-español, Madrid, San Lorenzo de El Escorial, 2005, p. 211.

37 S. Contreras Aguirre, “"Et certe opera Deus facit mediantibus causis secundis»: fray Luis de León y la determinación del derecho", en Olivar. Revista de literatura y cultura españolas, 21, 2014, pp. 3-14, consultado el 10 de octubre de 2016, URL: http://www.olivar.fahce.unlp.edu.ar/article/view/Olivar2014v15n21a02.

38 J. Román Zamora, Repúblicas del mundo, TeRCERA PARTE, p. $156 \mathrm{f}$.

39 De acuerdo con $\mathrm{O}^{\prime}$ Gorman ' $[. .$.$] cada pueblo, donde quiera que se hallare y por aislado que estuviere, tiene$ su propio destino que, sin embargo, no les es exclusivo, porque por encima de toda circunstancia contingente, se trata siempre del mismo y único destino de la humanidad. Y la razón es que la esencia en que se hacían partícipes a todos los hombres, además de vincularlos en la naturaleza como individuos de una misma especie, los ligaba en la historia en cuanto entes dotados de un alma inmortal, creados a imagen y semejanza de Dios y llamados a la salvación de la vida eterna. De esta suerte, todos los hombres sólo eran iguales por naturaleza, y en la historia eran prójimos, es decir, cercanos, con independencia de su mutuo desconocimiento, y en última instancia, eran hermanos, como hijos todos de un mismo padre que los convidaba a su mansión celeste". B. de Las Casas, Apologética historia sumaria, Tomo I, ed. preparada por Edmundo O'Gorman, con un estudio preliminar, apéndices y un índice de materias, Universidad Nacional Autónoma de México, Instituto de Investigaciones Históricas, México, 1967, Introducción, p. lxvi. 
la historia verdadera que convenía a la misiva del poder, una auténtica misión de estado. Y toda misión de estado lleva en su estructura el poder imperial, propiciando invectivas que ganaran el favor del interlocutor. En otras palabras, las crónicas de la sociedad del siglo colonizador expresan las relaciones de poder que se estructuran al interior de la institucionalidad propiciada por la corona española.

\section{Repúblicas del mundo como producción comunicacional.}

El estudio de una crónica cuyo autor se ha diluido en el mar de la vida corporativa del siglo xvi, deja claro que la oportunidad de conseguir información acerca del personaje es muy reservada. En este periodo "la identidad se constituye corporativamente. El reconocimiento social del individuo pasa por la pertenencia a corporaciones, y nunca a se realiza, como en la modernidad, con independencia a ella". Aquí el yo se encuentra institucionalizado, o mejor dicho, socializado normativamente, lo cual pone en predicamento la idea de que estos "escritores" pudieran ser considerados de libre pensamiento, pues "la singularidad del autor se desvanece en un mundo de poquísimos datos y, en una referencia, se sujeta a las convenciones de la representación de las personas por el sisma social estratificado"40. La transitoriedad es el elemento común de los hombres en las sociedades de soberanía, y lo que a ellos caracteriza es lo inefable, o para utilizar los términos precisos, el desvanecimiento de los individuos en la historia de Cristo. La misma escritura de la historia era tarea de monjes como copistas, calígrafos y un jefe del taller "en el que muchas veces recaía la «autoría» final, pero el proceso de elaboración de una obra mayor conllevaba todo un trabajo de equipo" "41. Ya lo decía el canonista Dámaso (h. 1215): "La Dignidad nunca perece, mientras que los individuos mueren todos los días"42. En un periodo donde la regla impone esta condición de posibilidad para hacer la historia, es oportuno repensar la función del autor al que comúnmente se le otorga mayor relevancia ${ }^{43}$, así introduciremos el análisis de la lógica retórica en las Repúblicas.

La crónica de Fray Jerónimo Román es un programa retórico con un único objetivo: persuadir a su interlocutor de las leyes y costumbres esenciales que las "gentes del orbe" tenían para poder vivir en compañía de los demás, esto es, la manera de hacer su gobierno siguiendo las disposiciones de la "luz natural". Es lo que se ha denominado "policía", una descripción figurativa de las formas de hacer justicia (gestión, administración) como el resultado positivo y valorado de un buen gobierno. Al igual que toda obra escrita, la crónica de éste rétor es un producto comunicativo social, a través de la cual se pueden observar las experiencias, reglas y valores que su comunidad compartía.

¿Qué implicación hay en pensar a una obra impresa como resultado de la comunicación? La propuesta de los sistemas sociales dice que la comunicación no se

40 A. Mendiola, Retórica, comunicación y realidad, op. cit., pp. 252, 349, 364.

${ }_{41}$ N. Durán, Retórica de la santidad: renuncia, culpa y subjetividad en un caso novohispano, Ciudad de México, UIA/El mundo sobre papel, 2008, p. 190.

42 E. H. Kantorowicz, Los dos cuerpos del rey. Un estudio de teoría política medieval, trad. Susana Aikin Araluce y Rafael Blázquez Godoy, Madrid, Akal, 2012, p. 381.

43 P. Chinchilla Pawling, "Las «formas discursivas». Una propuesta metodológica", en Historia y Grafia, 43, 2014 , pp. 15-40, aquí p. 20. He reinterpretado las preguntas elaboradas por esta autora para abrir camino al estudio a la producción contextualizada de la comunicación de las Repúblicas. 
podría dar si el receptor no entendiera el mensaje del emisor. Sólo cuando aquel ha comprendido el mensaje es que puede hablarse estrictamente de su inicio. El proceso se compone de mecanismos que organizan el contexto en el que ambos miembros participan. De tal modo que este vínculo no es un acontecimiento espontáneo, y se puede decir por eso que la comunicación es el producto de una operación, la cual se emplea para diferenciar algo, y tiene forma de observación. Observar no es un acto pasivo, sino activo: "cuando se observa se realiza algo" dice Alfonso Mendiola. En lo que respecta a los textos impresos, no son otra cosa que observaciones hechas socialmente mediante las cuales se describe lo real, cuya peculiaridad estriba en la internalización de reglas convencionales asumidas entre los distintos miembros. Los libros son medios que dan cuenta de cómo una sociedad observa el mundo según un orden de realidad específico. Son descripciones que saltan la percepción individual y se comparten en el lenguaje; esa es la razón del porqué para acceder a la realidad se requiere de repetir la operación que la instituyó. Por eso se dice que las sociedades construyen realidad bajo un régimen de lo visible y lo comunicable. Como ha señalado Hartog, "Describir es ver y hacer ver; significa decir lo que viste, todo lo que viste y nada más que lo que viste. Pero si no puedes decir lo que viste, no puedes ver lo que se dice: tú, lector u oyente, pero tampoco tú, testigo que relatas"44. Comunicar es un fenómeno que propicia el enlace de normas de orden discursivo. Para ello cada sociedad construye referencias o marcas que hacen posible la inteligibilidad de los acontecimientos. La consistencia de la realidad depende del procesamiento de estas marcas, ya que únicamente se puede observar algo cuando hay una distinción que deja ver esto y no lo otro. El desenvolvimiento de las convenciones sociales da cuenta de "guías" que propician la aceptación comunicativa. Es lo que se denominan "estructuras de expectativa". En la gama de información vertida por el libro, el receptor espera encontrar un contenido que propicia su aceptación comunicativa; mientras que el emisor (autor) presupone su reconocimiento. Las expectativas entre los interactuantes se atan a los criterios temporales de comprensión (aceptación o rechazo) y la comunicación puede entonces reproducir el marco general de sus convenciones. Las formas de recepción van a la par de los cambios de una época a otra, por lo que la relevancia de los relatos ha de estar determinada por la tradición literaria a la que se pertenece.

Las crónicas eran textos enmarcados en un régimen eminentemente oral y normativo, lo que significa que su oferta comunicativa se encontraba inscrita en el orden de lo emotivo ${ }^{45}$. Propiciar su aceptación dependía de la reproducción de valores que tienen que ver con las virtudes y no lo contrario a ellas. En cuanto forma discursiva la comunicación que las crónicas se proponen realizar - muy distinta a la comunicación científica del tipo "cognitiva"- se encuentra estilizada para cumplir con una función exclusiva: trasmitir enseñanzas de estricta tradición cristiana. Lo que ahí encontraremos son acontecimientos juzgados moralmente y no tanto su descripción objetiva. El lector de las crónicas sabía qué iba a encontrar, por eso se servía de ellas para su instrucción y deleite. La realidad que construyen estos productos comuni-

44 F. Hartog, El espejo de Heródoto. Ensayo sobre la representación del otro, Argentina, FCE, 2003, p. 236.

45 "La fijación misma, por y en la escritura, de una tradición que fue oral no necesariamente le pone fin ni la margina. Puede instaurarse cierta simbiosis o, al menos, cierta armonía: lo oral se escribe, lo escrito aparece como una imagen de lo oral; de cualquier forma, la referencia a la autoridad de la voz queda patente". P. Zumthor, $L a$ poesía y la voz en la civilización medieval, trad. José Luis Sánchez-Silva, Madrid, Abada editores, 2006 , p. 97. 
cativos no tiene posibilidad de modificar su experiencia ya que se rigen bajo un principio incuestionable: el de autoridad. Es una sociedad preocupada por separar el comportamiento conforme del disconforme apegándose a la sabiduría libresca; está preocupada por cultivarse en todo aquello que los haga auténticamente "humanos". Por eso decíamos que sus expectativas colocaban el deber ser por encima del ser. Como un cuanto sistema social, la aristocrática se distingue de su entorno en un proceso de reforzamiento estructural que moldea la apropiación de la diferencia. Para el caso de las "gentes con policía" que describió Fray Jerónimo, esto fue a partir de la distinción acá-europeo/allá-otro, lo humano/no humano, cristiano/nunca cristiano. Destaca cualidades que tienen que ver con los valores cristianos; recrimina aquellas conductas que contribuyen al daño de los demás muy a pesar de la "lumbre natural" impresa en el alma de todos los hombres; a veces por fuerza del diablo o bien por la inconstancia, su razón está nublada (la costumbre es mala consejera). Para eso el cristianismo había irrumpido en la historia, para enderezar sus caminos. Así se llega a la tesis de que, como un producto comunicacional, las Repúblicas estaban dirigidas a un público específico que comprendía la naturaleza normativa propugnada por textos que esperaban transmitir valores cristianos. Su público no encontraba ninguna apreciación efectiva de la alteridad, sino una enseñanza moral que trataba de recrear acontecimientos y circunstancias históricas para que el otro existiera (condiciones físicas, prácticas sociales etc., que eran el espejo de la sociedad occidental). El subproducto de estos mecanismos diferenciadores fue la implementación de esquemas reductores, los cuales otorgaban de facto un carácter colectivo a cada una de sus repúblicas. Una vez aceptado esto, a partir de ciertas costumbres se procedía a extrapolar el comportamiento característico de su sociedad: los indios son de alma noble, limpios y ascéticos, pero idólatras; los etíopes castigan los adulterios pero son profundamente carnales; los turcos son sanguinarios además de torpemente infieles; los chinos administran sabiamente la justicia pero están embaucados por el demonio a causas de su nigromancia, etc. ${ }^{46}$.

\section{Perennizar las diferencias: el pagano, el gentil.}

Fray Jerónimo fue un rétor que abordó el tema de la policía a partir de la extrapolación de costumbres que consideraba específicas para cada república. Con esto Fray Jerónimo Román otorgó un carácter colectivo al comportamiento de las variedades de gobierno. El razonamiento pretendía homogeneizar en un solo paso el estado del régimen político que hace distintivo a un grupo humano. Aunque los márgenes de las expectativas de esta sociedad son muy estrechos, en realidad la colectivización de los comportamientos termina por perennizar las diferencias, acentuando de una sola vez el orden en que se encuentran dispuestas fijamente todas las cosas en el mundo, según su estado natural, o lo que es igual, acorde al grado de razón natural que hacía a una civilización comportarse de una forma y no de otra. Se genera allí una separación infranqueable entre el mundo cristiano y el estrictamente pagano; en

\footnotetext{
46 "Un relato [...] es verosímil porque el personaje o los personajes del mismo hacen cosas que corresponden a su estatus social, además de que las acciones narradas hayan podido suceder en el tiempo que se dicen que sucedieron. La verosimilitud produce en el oyente un efecto de realismo, por lo que éste depende del campo de lo posible en una sociedad estratificada”. A. Mendiola, Retórica, comunicación y realidad, op. cit., p. 329.
} 
el primer caso, hace uso de la verdad revelada para desplegar sus fuerzas en favor del bien común; con los paganos, que comprenden el resto del universo, se compone a veces de virtudes a medias pero siempre son los vicios los que ganan la partida. Su inclinación a vivir juntos no es para alcanzar la redención, sino sólo para realizar las tareas más básicas: su pensamiento estaba velado. La estructura que el cronista dispuso para el orden de sus repúblicas es elocuente en este sentido:

Convenía así mismo que saliese primero la República Cristiana, como cosa santa y sagrada porque siempre han de ser preferidas las cosas divinas a la humanas, y lo bueno a lo no tal [...] También me moví a hacer esto, porque cuanto es de perfectos pintores, que cuando quieren labrar una obra famoso [sic], después que han hecho el rascuño y voscaxado [sic] la tabla, cuando quieren perfeccionar la obra, lo último que hacen es acabar el rostro; pero al gozar de las pinturas es al revés. Porque lo primero que miramos es el rostro, como lo más sustancial de la obra: y después contemplada la facción y la mano del maestro, paseamos los ojos por el resto de obra y allí vemos la gracia de los lexos [sic], cuan bien salen los colores, y a cada cosa damos la perfección: o si hay algo menos bueno, lo condenamos, y al cabo volvemos lo ojos al rostro como lo más principal [...] a esta misma república [de los indios] junté las de los turcos y moros, con todo lo que en este propósito se puede hallar. El poner estas Repúblicas contrarias a nuestra sancta fe me pareció acertado, porque no viviera bien entre lo sancto lo profano, y entre las tinieblas la $l u z^{47}$.

Todo esto se evidencia en su manera de llevar a cabo la única práctica que distingue a los hombres: su "religiosidad". Por mucho que el mundo pagano y gentil se esmerase en fructificar, su vinculación con lo divino se encontraba invertida y eso era suficiente como para quedar presas del engaño demoniaco. Fray Jerónimo dispone de una jerarquización conceptual que le permite asegurar el lugar excepcional de la República Cristiana:

Agora por la gracia de Dios, todos por todo el mundo nos nombramos Christianos, los Turcos, y Moros, por tales nos persiguen, y si los Hereges modernos nos llaman Papistas, no lo hazen porque no conocen que nosotros lo somos verdaderamente, mas porque el pueblo que van engañando no lo podrían atraer asi, si le quitasen el nombre de Christianos, y por eso a nosotros nos llaman Papistas, por descreditarnos, porque quitandonos el nombre de Christianos, y dandonos nuevo nombre el pueblo rudo, piensa que pues ellos se llaman Christianos, ellos lo son verdaderamente, pues conservan el nombre de Christo, que les predican ${ }^{48}$.

Según esto, los hombres que habitan el mundo actuaban dependiendo de su lugar natural por lo que son lo que hacen: de oriente a occidente, de sur a norte, o viceversa, el universo en el que las sociedades se desenvolvían se entendía como un cosmos cerrado donde cada habitante era parte de un mismo cuerpo y una misma historia, la Revelación. La vida pública podía regirse saludablemente cuando la luz divina interviene misteriosamente en su régimen. Un programa retórico de esta naturale-

\footnotetext{
47 J. Román Zamora, Repúblicas del mundo, op. cit., Segunda Parte, p. 3v.

48 Ibidem, Libro Primero, p. 81v. El subrayado es mío.
} 
za, evidencia, expone y comunica el orden tradicional de las distintas costumbres humanas en tanto resultado del espacio de experiencia moral que el interlocutor distinguía. Como cualquier cronista del siglo xvi, Fray Jerónimo describía "a partir de los presupuestos de su idea de la historia, articulada desde la retórica y sin intención de observación etnológica"49. Hubo la necesidad de apropiarse del espacio del otro a partir de la escritura; y esto significa ocuparlo gráficamente a parir de imágenes que lo sitúan como habitante del más allá, muy distinto del acá-europeo. Sin ningún concepto que los antiguos utilizaran, el resonante mundo medieval clasificó regiones y habitantes distintos a ellos siguiendo parámetros de irresoluble extrañeza y lejanía.

El etnos griego que significa raza o pueblo, al ser latinizado tomó el sentido de "pagano". Aún más, se carecía de un término similar a la idea actual de "cultura" [...]. En razón de estas carencias conceptuales, el Otro que está allá fue interpretado medievalmente en relación con su paganismo e idolatría, como también lo hicieron las crónicas de Indias. Estas dos categorías de amplia trayectoria de la cristiandad sirvieron para intentar comprender costumbres, hábitos y creencias diferentes a las occidentales, siempre leídas desde el punto de referencia del viajero, su $a q u i^{50}$.

Para Borja Gómez los imaginarios construidos por viajes a otras tierras definieron una realidad (textual) que no siempre ha sido vista en términos a la tradición retórica, y aunque la función de describir el mundo antiguamente carecía de las herramientas y categorías para enfrentar y entender a eso que se llama otro, en realidad sólo se pudo echar mano de recursos que justificaban el aquí-europeo del cronista: los clásicos, la Biblia, las leyendas o la teología. El lento despertar de una conciencia es el resultado del impacto que ocasionó el "fenómeno de la intersubjetividad, lo que conllevó un largo proceso de acercamiento para comprenderlo". Podría decirse que este era un proceso de asimilación del entorno que, sin embargo, no podía prescindir de una marca, la cual sirvió para moldear la apropiación de la diferencia. Una marca (distinción), "hacía la referencia a la noción de frontera, que designaba «lo que está en frente», una especie de territorio periférico que estaba articulado por la imprecisión de los límites de aquí y allá". Evidentemente esto no implica una tarea acerca de la aprehensión de alteridad en cuanto tal, sino simplemente de "encontrar la diferencia del observado con respecto a su cultura, acto seguido comparaba las jerarquías de valores que percibía con respecto a las suyas propias, y, finalmente, formulaba un juicio favorable o desfavorable" ${ }^{51}$. Era inevitable cruzar la posibilidad de acercarse definitivamente al otro, toda vez que éste no tenía otra salida que identificarse con lo que está fuera, lejos, vacío, peligroso, prohibido, idólatra, o hasta demoníaco. En este viaje con retorno seguro se estaba completamente consciente de que el espacio (el interior, el aquí-europeo) debía preservase ante el afuera amenazante, presto a desbordarlo. Por eso la naturaleza de este viaje a las repúblicas consistía en retornar al punto de partida del narrador, el lugar de enunciación retórico. En la conquista

\footnotetext{
49 J. H. Borja Gómez, Los indios medievales de fray Pedro de Aguado: construcción del idólatra y escritura de la historia en una crónica del siglo XVI, Bogotá, CEJA, Instituto Colombiano de Antropología e Historia/Universidad Iberoamericana, 2002, pp. 96.

50 Ibidem, p. 29 ss.

51 Ibidem, pp. 28-33.
} 
española de las Indias, continúa Borja Gómez, hubo una tarea fundadora en cuanto instrumento "para construir un origen convertido en discurso que lo actualizaba y lo mantenía vivo como memoria histórica. La escritura conllevaba mecanismos de negación de las diferencias, tras la búsqueda de la homologación de las identidades, proceso que lo encontramos en los antecedentes de escribir al Otro".

Existió una utilidad práctica en generalizar bajo una misma categoría al conjunto de costumbres que se pretendían conducir: preservar a toda costa una oposición entre los que estaban dentro del orden de la gracia y los que aún permanecian, por ignorancia o por rechazo a la verdadera religión, en una condición corrupta. Nos encontramos ante un proceso de construcción de fronteras morales y étnicas al interior de una sociedad, aunque diferenciada en razón a su origen histórico incompatible. Por eso se habla de reducción de diversidades culturales a una sola condición corrupta: paganos, herejes, infieles. Cabe resaltar que toda categoría homogeneizante de ésta índole no tienen ningún sentido sin las relaciones de poder mediadas por una distinción elemental: naturaleza/gracia, creación de Dios corrompida por el pecado original/participación en los sacramentos ${ }^{52}$. Juan Carlos Estenssoro ha precisado el fenómeno de acercamiento y distanciación que la Iglesia ejerció para domesticar las simulaciones diabólicas del mundo indiano, que para nuestro caso es un criterio perfectamente extensible a la escritura retórica de Fray Jerónimo Román, quien apropió el espacio del otro homologando las identidades de las distintas repúblicas a través de la invención de fronteras étnicas impermeables:

Pero si la Iglesia redefine constantemente la fe para eternizar el proceso de evangelización, Occidente renuncia también recurrentemente a verse en el espejo de los indios. Todo aquello que los indios creen, les pertenece exclusivamente, y pasa a formar parte de una esencia que, al ser atemporal, estaría anclada en el pasado remoto anterior a todo encuentro (garantía tranquilizadora de que no puede pertenecer sino a ellos). En ese sentido la Iglesia no sólo ejecutaba una labor eficaz de construcción y reconstrucción de las fronteras étnicas, sino que asumía éstas plenamente ${ }^{53}$.

Los discursos acerca de la historia desmembrada retóricamente no pretendía valor "artístico" alguno y sí una argumentación normativa de los acontecimientos. La conclusión que arrojan estos textos según el conjunto intencional de la distinción persuasión/disuasión, “corresponde a reglas que reflejan más que fórmulas estéticas, sino que definen quienes tienen la autoridad para hablar y cuál es el conocimiento legítimo". La historiografía del siglo xvi, prescrita bajo los esquemas providenciales, es consubstancial a "las expresiones morales cortesanas, que más allá de fórmulas retóricas, son otra modo de violencia y conquista" 54 . Las alegorías implícitas en las descripciones históricas (corpus mysticum, "el alma del cuerpo es el gobierno", "república universal") ${ }^{55}$, están implicadas en el proceso del expansionismo europeo,

52 A. Mendiola, Retórica, comunicación y realidad, op. cit., p. 70.

53 J. C. Estenssoro, "El simio de Dios: los indígenas y la Iglesia frente a la evangelización del Perú, siglos XVIXVII”, en Bulletin de l'Institut français d'études andines, vol. 30, 3, 2001, pp. 455-474, aquí p. 472.

54 J. Rabasa, De la invención de América. La Historiografia española y la formación del eurocentrismo, Ciudad de México, UIA-Fractal, 2009, pp. 22-23.

55 Esta versión del corspus mysticum christi, fue readaptada después y no fue hasta pasado el siglo xii que se retomó ante los intereses políticos de autosuficiencia secular. Según Ernst Kantorowicz, la aparición de bula Unam 
por ello los esquemas retóricos son violencia y conquista construidas a partir de una narrativa cortesana-cristiana ávida de honor y poder. La formación del discurso colonial durante el siglo xvi es la historia occidental escrita sin oposiciones, que conquista por su poder epidíctico y crea condiciones para la escritura de los otros:

[...] los textos, mapas, íconos, y otros productos culturales deben considerados artificios retóricos y no como depositarios de datos desde los cuales una verdad factual podría ser construida. La retórica, en este sentido, no es simplemente un arte de la persuasión, sino también implica juegos estratégicos que constituyen formas de subjetividad y producen un "efecto de realidad" 56 .

\section{Conclusión}

Nuestra apelación al pasado nos ha llevado al lugar desde donde se produce el discurso de nuestra crónica: el programa retórico de Fray Jerónimo Román Zamora debe entenderse como la construcción de un espacio histórico a partir de un plexo de expectativas cargadas con normas de valor social. En las expectativas se preservan lo que para esta sociedad es enteramente valioso, de tal modo que las reacciones ante una posible frustración se expresan en términos del deber ser y no en el ser. Quiere decir que toda irritación a la expectativa circula al interior de las condiciones del sistema y no es un cambio fuera de él, lo que implicaría una modalidad cognitiva que sí podría poner en discusión los saberes convenidos. No se aspira a producir conocimiento, sino a re-producir el horizonte cultural que alguna autoridad ya ha dicho. "Selecciona un estilo normativo de expectativa, cuando cree que las expectativas deben mantenerse incluso en caso de una decepción, porque las considera justificadas. Este tipo de estructuras cognitivas (conocimientos almacenados) en el siglo xvi son las teológicas" 57 .

El interlocutor cortesano, destinatario de esta oferta comunicativa, encontrará aquí conocimiento que le servirá para edificarse y deleitarse. Dicho de otra forma, para que el rey y sus funcionarios estén informados de sanas/nocivas prácticas de gobierno en varias partes del mundo y que pueden ejecutarse, o bien evitarse, todas las veces en que los acontecimientos ameritasen decisiones de recto juicio y razón natural. La historia del mundo tenía "buenos y malos hombres", por eso la humanidad requería de un orden incesante que evitara su amenazante caída.

Como un producto comunicativo, la crónica da cuenta de cómo una sociedad observa el mundo del debido orden público, así que cuando abordamos este texto lo que hicimos es observar el modo en que se observaba el mundo retóricamente. En lo que aquí corresponde, son convenciones condensadas tipográficamente cuyo principio es propiciar la aceptación comunicativa a partir de lo que el receptor espera encontrar en el interior de la obra, en otras palabras, es acondicionar la oferta comu-

sanctam del papa Bonifacio viii fue la más lapidaria y contundente respuesta a los sucesos: "En razón de la fe estamos obligados a creer en una santa Iglesia, católica y también apostólica... sin la cual no hay ni salvación ni remisión de los pecados... que representa un cuerpo místico cuya cabeza es Cristo, y la cabeza de Cristo es Dios". E. H. Kantorowicz, op. cit., p. 210.

56 J. Rabasa, op. cit., p. 27.

57 A. Mendiola, Retórica, comunicación y realdad, op. cit., p. 145. 
nicativa a través de expectativas que delimitan la posibilidad de que aquella ocurra (contingencia). Ordenar la variedad de cosas públicas, era ocasión para que hombres con distintas funciones al servicio del rey pudieran contribuir con la espada, o desde la pluma, en la tarea de integrar el orbe a la política que el deber moral exigía. Fray Jerónimo Román insiste en distinguir gentes con república, calificándolas con mayor o menor policía, no porque fueran meramente un agregado de personas, sino en cuanto emisor, él presuponía cuáles eran los requisitos morales convenientes para la salud de la comunidad, de esta manera separaba definitivamente a las sociedades aberrantes con conductas marcadas por el pecado, llámense gentiles y paganos. Para este rétor era obvio que todas las repúblicas habían portado máculas que les impedía alcanzar a ver el auténtico conocimiento de la policía. Lo importante era que sólo la cristiana tenía la credibilidad para asumir el ordenamiento de las demás.

Gentiles, paganos, o hasta infieles, las crónicas no trataban su presencia singular en sí, sino de cómo eran vistos. Es la razón de por qué hablar de una apropiación del espacio gentil-pagano a través de la escritura, consiste en implementaban artificios que hicieran del relato algo verosímil para el público (comparaciones, amplificaciones, digresiones y otros); herramientas por lo demás que permitían extrapolar su carácter colectivo, perennizando de este modo la distinción entre cristianos y aquellos que poseían un comportamiento disconforme, ajeno y extraño. Un sistema de gobierno premoderno no esperaba ganar experiencia para futuros procesos políticos, que de todos modos estaban en marcha, sino satisfacer una estructura de conocimiento que controlara las funciones y deberes de cada escaño, luego entonces, para orientar las decisiones sociales según su valoración moral (autorreproducción de expectativas). Es interesante ver que la noción de república fuera utilizada para responder el origen y gestación de la inclinación de los hombres a juntarse, pero esencialmente había funcionado como un sello que prefiguraba los respectivos lugares ocupados por los habitantes del orbe. Se trata de una historia con distintas gentes que se corresponde libremente con un plan divino, donde el carácter contingente de las criaturas y los acontecimientos, su libertad y sus inclinaciones, estaban administrados en una jerarquía misteriosa. A todas las repúblicas les concernía descifrar ese misterio, pero en su estado de agrupaciones temporales, participaban imperfectamente de la razón eterna, por eso su organización de la vida estaba condicionada por la historia y dañada por el pecado. 